\title{
Bir delik açma aparatı
}

\section{A drilling apparatus}

\author{
Mustafa Akkaya ${ }^{1}$, Murat Bozkurt ${ }^{2}$ \\ ${ }^{1}$ Ankara Yıldırım Beyazıt Üniversitesi Tıp Fakültesi, Ortopedi ve Travmatoloji Ana Bilim Dalı, Ankara Şehir Hastanesi, Ankara \\ ${ }^{2}$ Ankara Yıldırım Beyazıt Üniversitesi Tıp Fakültesi, Ortopedi ve Travmatoloji Ana Bilim Dalı, Ankara
}

Bu buluş, ön çapraz bağ rekonstrüksiyon ameliyatlarında kullanılan, femoral ve tibial tünellerin hazırlanması sırasında diz içerisinde dönerek delme işlemi yapan delme aparatı yerine bir delik açma aparatının kullanıldığı ve bu sayede eklem içerisine kemik parçalarının düşmesinin engellendiği, ayrıca kemik-tendon iyileşmesinin gerçekleşeceği ara yüzeyde dönerek delme işlemi sırasında oluşabilecek termal hasarın önlendiği bir delik açma aparatı ile ilgilidir.

Anahtar sözcükler: ön çapraz bağ; rekonstrüksiyon; tünel

\section{T. C. Türk Patent Enstitüsü'ne Faydalı Model Belgesi için Başvuru Bilgileri ${ }^{[1]}$}

Başvuru bilgileri Tablo 1'de gösterilmiştir. ${ }^{[1]}$

Tablo 1. Başvuru bilgileri ${ }^{[1]}$

$\begin{aligned} & \text { Başvuru numarası: } 2011 / 11906 \\ & \text { Başvuru tarihi: } 01.12 .2011 \\ & \text { Başvuru şekli: } \quad \text { Ulusal başvuru } \\ & \text { Evrak numarası: } 2011-G-329640 \\ & \text { Evrak tarihi: } 01.12 .2011 \\ & \text { Tescil numarası: } 201111906 \\ & \text { Tescil tarihi: } 21.07 .2014 \\ & \text { Koruma tipi: } \text { Incelemesiz patent } \\ & \text { Başvuru sahipleri: } \text { Murat Bozkurt } \\ & \text { Buluş sahipleri: } \text { Murat Bozkurt, } \\ & \text { Mustafa Akkaya, Ahmet Fırat }\end{aligned}$

The present invention is based on the use of a perforation apparatus instead of the drilling apparatus (drill) that rotates in the knee during the preparation of femoral and tibial tunnels, which is used in anterior cruciate ligament reconstruction surgeries, thereby preventing the falling of bone fragments into the joint, and in the intermediate period where bone-tendon healing takes place. It relates to a drilling apparatus that prevents thermal damage that may occur during the rotating drilling on the surface.

Key words: anterior cruciate ligament; reconstruction; tunnel
FAYDALI MODEL BELGESI - No: TR 201111906 B[1]

\author{
Teknik Alan ${ }^{[1]}$
}

"Bu buluş, artroskopik ön çapraz bă̆ rekonstrüksiyon ameliyatlarında kullanılan bir delik açma aparatı ile ilgilidir."

\section{Önceki Teknik/Teknikler ${ }^{[1]}$}

"Diz ekleminin stabilitesinde dört önemli bă̆görev alır. Bunlardan ikisi yan bağlar diğer ikisi ise ön ve arka çapraz bağlardır. ${ }^{[2]}$ Ön çapraz bağ (ÖÇB), tibianın femura göre öne doğru kaymasını sınırlandırarak ve dizin dönüş hareketlerini kısıtlayarak eklemin sabitlenmesinde önemli rol oynar ve eklemdeki streslerin azaltılmasını sağlar. ${ }^{[3]}$

ÖÇB cerrahisinde kullanılan farklı teknikler vardır. ${ }^{[4]}$ En sık tercih edilen ise otogreft ile ÖÇB rekonstrüksiyonudur. ${ }^{[5]}$ Cerrahi teknik olarak artroskopik yöntemler tercih edilmekte olup açık cerrahiler artık terk edilmiştir. Artroskopik ÖÇB rekonstrüksiyon cerrahisinde kullanılan

- İletişim adresi: Doç. Dr. Mustafa Akkaya, Ankara Yıldırım Beyazıt Üniversitesi, Ortopedi ve Travmatoloji Ana Bilim Dalı, Ankara Şehir Hastanesi, 06800 Ankara, Türkiye Tel: 0312 - 5226000 e-posta: makkaya@outlook.com ORCID iD: 0000-0002-2694-4208

- Geliș tarihi: 6 Kasım $2020 \quad$ Kabul tarihi: 16 Kasım 2020

Murat Bozkurt, ORCID iD: 0000-0001-8160-5375 
otogreftler sıklıkla hamstring ya da patellar tendonlar olarak tercih edilmektedir. Kullanılacak greftlerin eklem içinde hareketsiz kalarak sabitlenmesi için çeşitli biyo-uyumlu vidalar ya da askı sistemleri ile tespitleri yapılabilmektedir. ${ }^{[6]}$ Standart teknikte kullanılacak greflerin yerleştirileceği kemik tüneller oyucular yardımı ile kemikte delme işlemi yapılarak oval olarak açılmaktadır. ${ }^{[7]} \mathrm{Bu}$ delme işlemi sırasında kemik dokuda zayıflama gerçekleşmekte ve ayrıca eklem içine kemik artıkları düşmektedir. Bu artıkların eklem içinde her zaman temizlenebilmesi mümkün olmamaktadır."

\section{Buluşun Kısa Tarifi ${ }^{[1]}$}

"Bu buluşun amacl; kararlılığı daha iyi olan ve daha iyi bir kemik-tendon iyileşmesi sağlaması planlanan bir delik açma aparatı geliştirmektir. Bu buluşun bir diğer amacı, eklem içerisine kemik parçalarının düşmemesini săglayan bir delik açma aparatı gerçekleştirmektir.”

\section{Buluşun Detaylı Açıklanması ${ }^{[1]}$}

"Ön çapraz bağ rekonstrüksiyonu sırasında femoral tünelin hazırlanması bir delici yardımı ile gerçekleştirilmektedir. Artroskopik olarak gerçekleştirilen bu işlemde öncelikle ÖÇB'nin femoral ayak izinin olduğu noktalar belirlenmektedir. Bu belirlenmenin ardından Şekil 1'de gösterilmiş olan tercihen altıgen bir geometrik forma sahip olan delicinin (Şekil 1, 2 ile gösterilen bölüm) femurda uygun şekilde ilerlemesi adına kılavuz tel femoral ayak izinden gönderilir. Devamında delicinin merkezinde bulunan ve kılavuz telin içinden geçmesini sağlayan kanaldan (Şekil 1, 5 ile gösterilen bölüm) delicinin eklem içinde ilerleyecek sivri ucu (Şekil 1, 3 ile gösterilen bölüm) geçirilir. Ardından delici eklem içi boyunca ilerletilir ve femoral tünelin hazırlanması için kemiğe temas ettirilir. Takiben delicinin arkasında bulunan yivli bölüme (Şekil 2, 10 ile gösterilen bölüm) üzerinde hareketli çakma aparatının (Şekil 4) kullanılarak çakılmasının sağlayan çakıcı sistem (Şekil 3) yine yivli uç kısmı sayesinde (Şekil 3, 9 ile gösterilen bölüm) döndürülerek monte edilir. Montaj gerçekleştikten sonra hareketli çakma aparatı üzerinde ileri ve geri hareketler sağlayarak güç uygulamasına imkan veren çakıcı yolu (Şekil 3, 7 ile gösterilen bölüm) sayesinde altıgen delici aparat kemik dokuda önceden belirlenmiş greft tüneli boyu kadar eklem içinde görülebilen milimetrik olarak işaretlenmiş uç kısmı (Şekil 1, 3 ile gösterilen bölüm) takip edilerek ilerletilir. Eklem içerisinde dönerek delme yapan aparatlar yerine bir delik açma aparatının kullanılması sayesinde eklem içine kemik parçalarının düşmesi engellenmekte aynı zamanda greft-kemik ara yüzü çakarak ilerletme işlemi ile altıgen tünel duvarlarına kemik dokuyu sıkıştırarak daha sağlam bir şekilde hazırlanmaktadır."

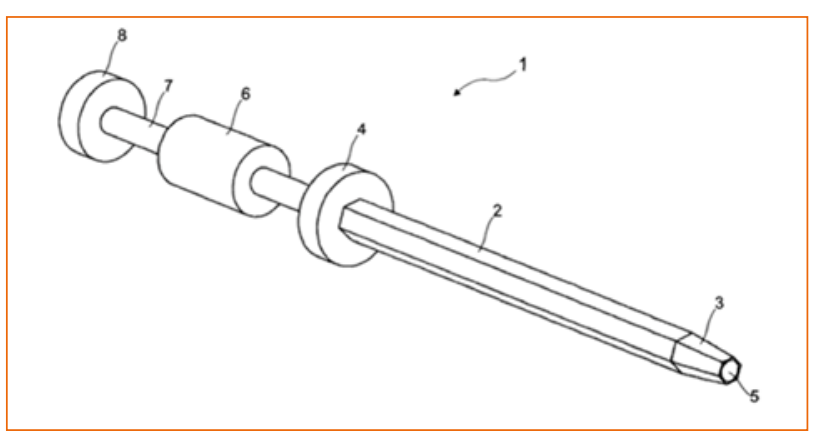

Şekil 1. Bir delik açma aparatının perspektif görünüşüdür (2, delici; 3, işaretli delme ucu; 4, delici başı; 5, delici kanalı; 6, çakıcı; 7, çakıcı yolu; 8, çakıcı koruması).[1]

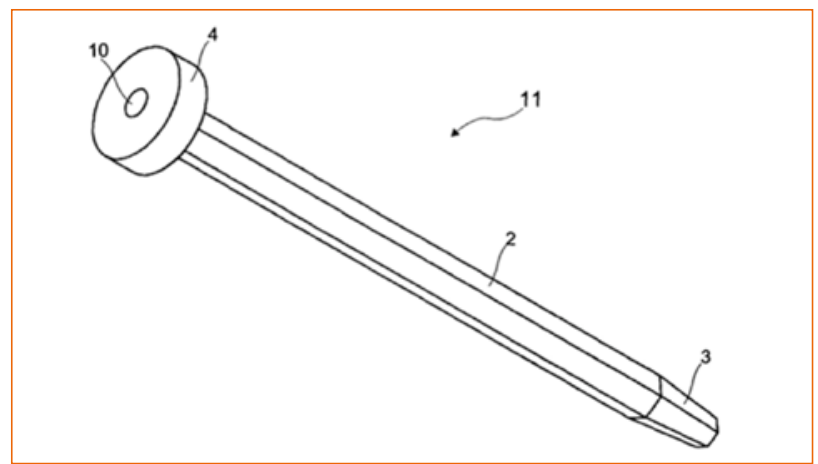

Şekil 2. Bir delik açma aparatının alt parçasının perspektif görünüşüdür (10, yiv yolu; 11, alt parça). ${ }^{1]}$

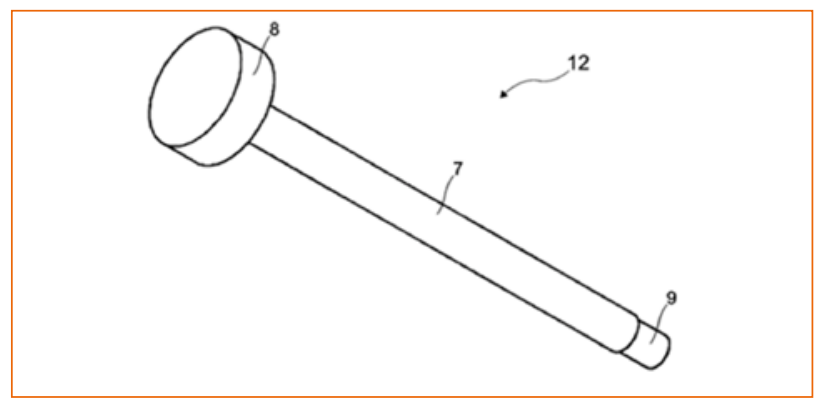

Şekil 3. Bir delik açma aparatının üst parçasının perspektif görünüşüdür ( 9 , yiv başı; 12 , üst parça). ${ }^{[1]}$

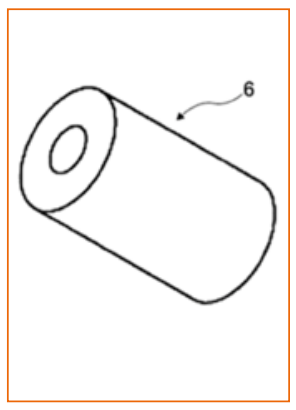

Şekil 4. Bir delik açma aparatının çakıcısının perspektif görünüşüdür. ${ }^{[1]}$

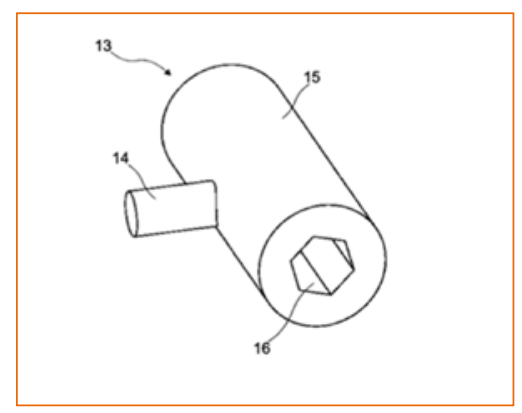

Şekil 5. Bir delik açma aparatının greft ölçücüsünün perspektif görünüşüdür (13, kontrol elemanı; 14, yiv başı; 15 , tutucu yüzey; 16 , greft ölçer). ${ }^{[1]}$ 


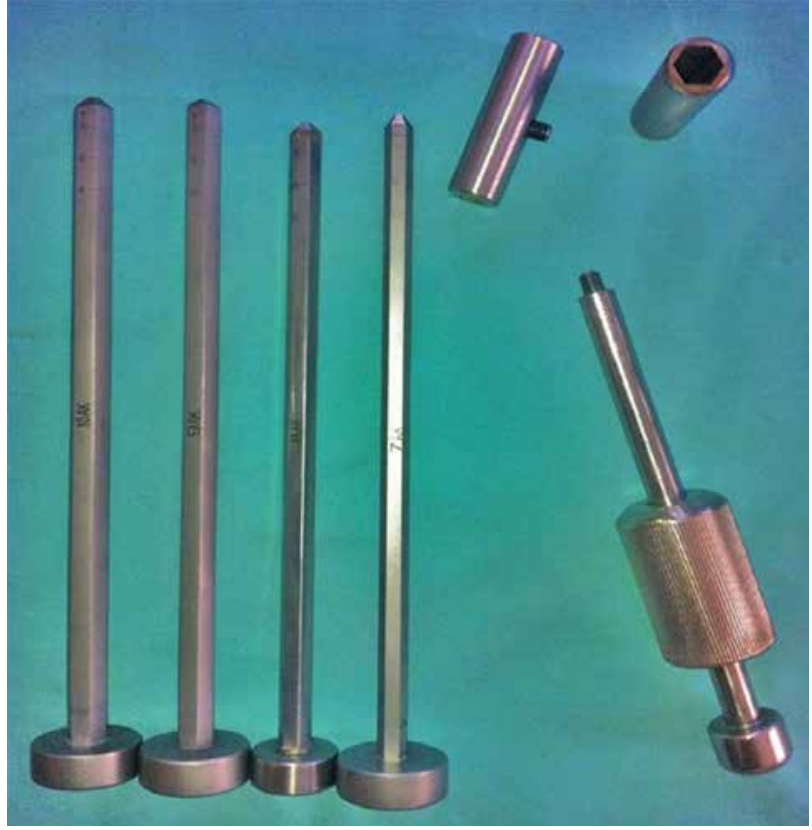

Şekil 6. Farklı kalınlıklardaki delik açma aparatlarının görüntüsü. [1]

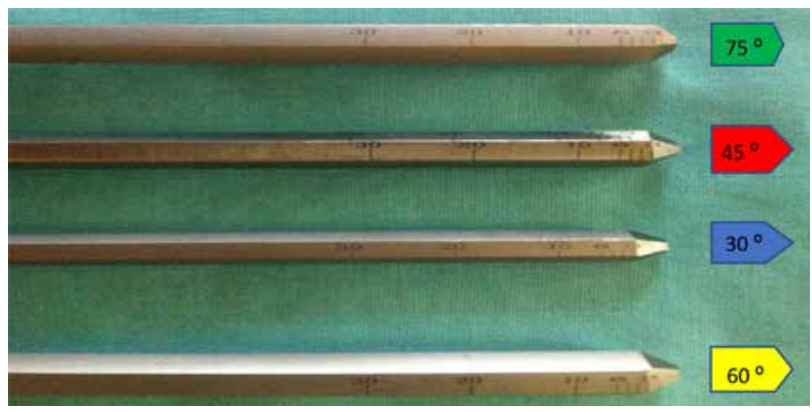

Şekil 7. Farklı açılardaki giriş uçlarına sahip delik açma aparatlarının görüntüsü. ${ }^{[1]}$

\section{İstemler ${ }^{[1]}$}

"1. ÖÇB cerrahisinde kullanılan, en temel hali ile kemikte dönerek delme işlemi yerine çakarak ilerletilen altıgen geometrik şekilli bir delici olmalıdır.

2. Delicinin bir ucu kemik dokuda daha rahat ilerletilebilmesi adına daha ince ve sivri olmalı, ek olarak kemik içinde açılacak tünel boyunun belirlenebilmesi için milimetrik olarak işaretlenmiş olmalıdır.

3. Delicinin eklem içinde uygun yönde ilerlemesini sağlayan kılavuz telin delici aparat içinden geçmesini sağlayan bir kanal içermelidir.

4. Delicinin eklem içinde çakılarak ilerletilmesini sağlayan ve yivler yardımı ile monte edilebilen bir çakıcı yolu olmalıdır.
5. Çakıcı yolu üzerinde ileri-geri kayarak çakma işlevi görebilen bir çakma aparatı olmalıdır.

6. Tercihen altıgen bir geometriye sahip olan ve delik açma aparatı ile benzer genişliğe sahip, operasyon sırasında hazırlanan greftin kalınlığını ölçmek için kullanılan bir greft ölçücü olmalıdır.”

\section{YAZARLARIN KONUYLA ILGILI ÇALIŞMALARI}

ÖÇB diz ekleminde tibianın anterior translasyonunu engelleyen en önemli yapıdır. Tibial ve femoral ayak izlerine göre yapışma alanları kişiden kişiye farklılık gösterebilmektedir. ÖÇB yırtıkları en sık non-kontak (temasın olmadığı) spor yaralanmalarına bağlı görülmektedir. Yırtık mekanizması sıkıkla tibianın iç rotasyona femurun ise dış rotasyona zorlandığı dönme hareketleri olarak bilinmektedir. Ayrıca femurdaki çeşitli anatomik varyasyonlara (dar interkondiler notch, vb.) bağlı olarak da ÖÇB yırtıklarının sıklığında artış görülmektedir.

ÖÇB rekonstrüksiyonuna aday hastaların sıklıkla diz ağrılarına eşlik eden instabilite şikayetleri de bulunmaktadır. ${ }^{[8]}$ Hastalara uygulanacak rekonstrüksiyon cerrahisinde artroskopik prosedürler tercih edilmekte olup kullanılacak greftin eklem içindeki yerleşimi için güncel literatürde anatomik femoral ve tibial tünellerin açılması kabul görmektedir. ${ }^{[7]}$ Tünel yerleşimleri ÖÇB cerrahisinde uzun greft sağ kalımı için çok önemlidir. Dolayısı ile ÖÇB cerrahisinde başarının anahtarı kemik tünellerden geçmektedir.

Mevcut cerrahi tekniklerde femoral ve tibial tüneller dönerek delme işlemi yapan deliciler ile açılmaktadır. Bu işlem sırasında eklem içine birçok residüel kemik parçası düşmektedir. Tamamı temizlenemeyen bu parçalar ileride eklem içinde takılma, aşındırma ve rahatsızlık hissiyatı oluşturabilmektedir. Ayrıca dönerek delme işlemine kemik tüneller oval bir şekilde açılmaktadır.

Geliştirmiş olduğumuz tünel açma aparatının çalışma mekanizması ise delme işlemi sırasında spongioz kemikte oluşan boşalma ve eklem içine kemik parçalarının düşmesi yerine çakma işlemi ile tünelin açııması sırasında spongioz kemik parçalarının tünel duvarına impakte olmasına dayanır. Ayrıca geometrik olarak altıgen şekillerin mukavemetinin oval şekillere göre daha fazla olduğu da göz önünde bulundurularak delme aparatı altıgen şekilli dizayn edilmiştir. Rekonstrüksiyon sırasında kullanılacak greftlerin kalınlıklarının farklı olabileceği de düşünülerek delme aparatları farklı kalınlıklarda tasarlanmıştır (Şekil 6). Ayrıca açılan tüneller içinde greftlerin tünel tavanı ile temas mesafesi[9] de düşünülerek delme aparatlarının uç kısımları farklı açılarda da tasarlanmış (Şekil 7) ve greft-tünel tavan mesafesinin optimum olması amaçlanmıştır. 


\section{KAYNAKLAR}

1. Bir Delik Açma Aparatı. T. C. Türk Patent Enstitüsü. Incelemesiz Patent. No: TR 201111906 B. https://portal. turkpatent.gov.tr/anonim/arastirma/patent/detayli

2. Clasby L, Young MA. Management of sports-related anterior cruciate ligament injuries. AORN J 1997;66:609$25,628,630$; quiz 632-6. https://doi.org/10.1016/ s0001-2092(06)62914-1

3. Shelbourne KD, Mollabashy A, De Carlo M. Acute anterior cruciate ligament injury. Indiana Med 1990;83:896-900. https://pubmed.ncbi.nlm.nih.gov/2280061/

4. Aglietti, P Zaccherotti G, Menchetti PP, De Biase P. A comparison of clinical and radiological parameters with two arthroscopic techniques for anterior cruciate ligament reconstruction. Knee Surg Sports Traumatol Arthrosc 1995;3:2-8. Crossref

5. Ahlden M, Samuelsson K, Sernert N, Forssblad M, Karlsson J, Kartus J. The Swedish National Anterior Cruciate Ligament Register: a report on baseline variables and outcomes of surgery for almost 18,000 patients. Am J Sports Med 2012;40:2230-5. Crossref
6. van Eck CF, Schreiber VM, Mejia HA, Samuelsson K, van Dijk $\mathrm{CN}$, Karlsson J, Fu FH. "Anatomic" anterior cruciate ligament reconstruction: a systematic review of surgical techniques and reporting of surgical data. Arthroscopy 2010;26:S2-12. Crossref

7. Petersen W, Forkel P, Achtnich A, Metzlaff S, Zantop T. Anatomic reconstruction of the anterior cruciate ligament in single bundle technique. Oper Orthop Traumatol 2013;25:185-204. Crossref

8. Deveci A, Cankaya D, Yılmaz S, Özdemir G, Arslantaş E, Bozkurt M. The arthroscopical and radiological corelation of lever sign test for the diagnosis of anterior cruciate ligament rupture. Springerplus 2015;4:830. Crossref

9. Firat A, Çatma F, Tunc B, Hacihafizoglu Ç, Altay M, Bozkurt $M$, Kapicioglu MSS. The attic of the femoral tunnel in anterior cruciate ligament reconstruction: a comparison of outcomes of two suspensory femoral fixation systems. Knee Surg Sports Traumatol Arthrosc 2014;22:1097-105. Crossref 